\title{
Late recovery of atrioventricular conduction after pacemaker implantation for complete heart block associated with surgery for congenital heart disease
}

\author{
Anjan S. Batra, MD \\ Winfield J. Wells, MD \\ Kathy W. Hinoki, RN, MSN \\ Robert A. Stanton, MD \\ Michael J. Silka, MD
}

From the Children's Hospital Los Angeles, Keck School of Medicine, University of Southern California, Los Angeles, Calif.

Received for publication June 24, 2002; revisions requested Sept 3, 2002; revisions received Oct 24, 2002; accepted for publication Dec 2, 2002.

Address for reprints: Winfield J. Wells, MD, Children's Hospital Los Angeles, Department of CardioThoracic Surgery, MS66, 4650 Sunset Boulevard, Los Angeles, CA 90027 (E-mail: wwells@chla.usc. edu).

J Thorac Cardiovasc Surg 2003;125:1291-3

Copyright () 2003 by The American Association for Thoracic Surgery

$0022-5223 / 2003 \$ 30.00+0$

doi:10.1016/S0022-5223(03)00198-3
Objectives: Pacemaker implantation is a standard recommendation for patients with persistent complete heart block following surgery for congenital heart disease. This study was performed to determine the incidence and clinical significance of late recovery of atrioventricular conduction following pacemaker implantation.

Methods: Between 1990 and 2001, 5662 open cardiac procedures for congenital heart defects were performed at our institution. The postoperative course of all patients with complete heart block in whom a permanent pacemaker was implanted was followed on a monthly basis, by either clinical or transtelephonic follow-up.

Results: A total of 72 patients with persistent postoperative complete heart block underwent pacemaker implantation. After insertion of the pacemaker, recovery of atrioventricular conduction was recognized in 7 of 72 patients $(9.6 \%)$ at a median of 41 days (18-113 days) after the initial cardiac operation. These included 3 patients with ventricular septal defect, 2 with ventricular inversion or single ventricle, and 1 each with left ventricular outflow tract obstruction and atrioventricular septal defect. During a mean follow-up of $4.4 \pm 2.6$ years, there was no late recurrence of heart block. Three patients had residual right bundle branch block and 1 had first-degree atrioventricular block.

Conclusions: Atrioventricular conduction may return in a small but significant percentage of patients following pacemaker implantation for complete heart block associated with congenital heart surgery. When recovery of atrioventricular conduction occurs within the first months after surgery it appears reliable, which suggests that lifelong cardiac pacing may not be necessary in these individuals.

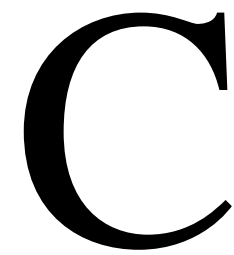

omplete heart block (CHB) is one of the major complications of surgery for congenital heart disease. Although the incidence has decreased from $>10 \%$ in the $1960 \mathrm{~s}^{1}$ to $1-3 \%$ in the current era, ${ }^{2,3}$ postoperative $\mathrm{CHB}$ remains a significant cause of morbidity, increased cost, and decreased long-term survival. ${ }^{4}$ The highest incidence of CHB has been reported for surgical procedures involving a ventricular septal defect (VSD) or atrioventricular septal defect (AVSD), left ventricular outflow tract obstruction, or discordant atrioventricular (AV) connections. ${ }^{1,5-9}$

In a study of postoperative AV conduction block, Weindling reported that $>95 \%$ of patients who have recovery of AV conduction do so by postoperative day $9 .^{2}$ They concluded there was minimal benefit in delaying implantation of a permanent pacemaker beyond 9 days when CHB was persistent. More recently, it has been suggested that patients who have persistent complete AV block for even 24 to 48 
TABLE 1. Congenital heart defects with AV block and recovery of $A V$ conduction

\begin{tabular}{lccc}
\hline $\begin{array}{l}\text { Congenital } \\
\text { heart defect }\end{array}$ & $\begin{array}{c}\text { Total no. } \\
\text { with AVB }\end{array}$ & $\begin{array}{c}\text { With AV } \\
\text { recovery (no.) }\end{array}$ & $\begin{array}{c}\text { With AV } \\
\text { recovery (\%) }\end{array}$ \\
\hline VSD & 35 & 3 & 8.5 \\
AVSD & 9 & 1 & 11 \\
LVOTO & 11 & 1 & 9 \\
DAVC & 18 & 2 & 11
\end{tabular}

VSD, Ventricular septal defect; AVSD, atrioventricular septal defect; LVOTO, left ventricular outflow tract obstruction; DAVC, discordant atrioventricular connections.

hours following valve replacement should have pacemaker implantation. ${ }^{10}$ Other studies have reported the late development of CHB months to years after surgery for congenital heart disease. ${ }^{9,11-13}$

Conversely, the incidence and clinical significance of late recovery of AV conduction after surgical CHB when pacemaker implantation has been performed is unknown. Therefore, the purpose of this analysis was to determine the incidence of late recovery of AV conduction, the intermediate term follow-up of these patients, and factors potentially associated with recovery of AV conduction.

\section{Methods}

A review of our surgical and pacemaker databases was performed to identify all patients who underwent permanent pacemaker for postoperative CHB between 1990 and 2001. Patients with placement of a permanent pacemaker for congenital $\mathrm{CHB}$, sinus node dysfunction, or preoperative CHB were excluded.

The timing of permanent pacemaker implantation was based on clinical judgement and current American College of Cardiology/ American Heart Association (ACC/AHA) Guidelines. ${ }^{14}$ Transtelephonic pacemaker evaluation was performed on a monthly basis, with an overall $93 \%$ compliance rate for all patients. ${ }^{15}$ Clinical evaluation and pacemaker interrogation were performed at 1 week and 1 month after discharge, and then at recurrent 6-month intervals. The status of AV conduction was evaluated by ECG and interrogation with pacemakers implanted after 1995 to determine whether any ventricular pacing had occurred. The pacemakers were then temporarily reprogrammed to a VVI back-up mode at a low rate to allow for observation of any intermitted AV conduction. The integrity of AV conduction (when recovered) was also tested in patients with dual-chamber pacemakers by atrial pacing at rates of 100 to 140 beats/min.

Factors tested for correlation with late return of a conducted rhythm included type of congenital heart defect, postoperative day at which a pacemaker was implanted, and the time after implantation when AV conduction was first noted. Late recovery of AV conduction was defined as persistent recovery of AV conduction occurring at more than 14 days after the onset of $\mathrm{CHB}$.

\section{Statistical Analysis}

Discrete variables were compared using the Fisher exact test and continuous variables were compared using the $t$ test. Statistical
TABLE 2. Comparison of variables between patients with and without recovery of $A V$ conduction

\begin{tabular}{lccc}
\hline Variable & $\begin{array}{c}\text { Recovered } \\
(\mathbf{n}=\mathbf{7}) \\
\text { mean } \pm \text { SD }\end{array}$ & $\begin{array}{c}\text { No recovery } \\
(\mathbf{n}=\mathbf{6 5})\end{array}$ & \\
\hline mean \pm SD & $\boldsymbol{P}$ value* \\
Age at surgery (years) & $1.24 \pm 1.00$ & $1.96 \pm 2.66$ & .909 \\
Follow-up from implant (years) & $4.37 \pm 2.60$ & $5.20 \pm 3.46$ & .621 \\
Post-op at implant (days) & $7.43 \pm 3.60$ & $9.08 \pm 8.20$ & .560
\end{tabular}

*For continuous variables, the comparisons were made by the Wilcoxon two-sample test.

significance was assessed by a $P$ value of $<.05$. Statistical analysis was performed with the SAS System for Windows, Version 8, 1999 (SAS Institute, Inc, Cary, NC).

\section{Results}

During the 11-year study period, 5662 operations were performed on cardiopulmonary bypass at Children's Hospital of Los Angeles. Seventy-two patients (1.3\%) with persistent postoperative AV block underwent permanent pacemaker implantation.

Among the 72 patients requiring permanent pacing, 35 had closure of a VSD, usually as a part of a more complex procedure. Other surgical procedures associated with $\mathrm{CHB}$ were complex intracardiac repair of functional single ventricle or discordant AV connections $(n=18)$, relief of left ventricular outflow tract obstruction $(\mathrm{n}=11)$, and repair of an AVSD $(n=9)$. Most of the patients requiring a pacemaker for postoperative CHB were less than 1 year old, with a median age of 11 months ( 2 days to 11 years).

Persistent recovery of AV conduction was observed in 7 of the 72 patients $(9.7 \%)$. When tested for the discrete variables, there was no statistically significant difference between the patients who had recovery of AV conduction and those with persistent CHB. The type and number of congenital heart defects are summarized in Table 1. The postoperative day of pacemaker implantation was $7.4 \pm 1.4$ versus $9.0 \pm 1.0$ days and the mean age at which the pacemaker was initially implanted was $1.2 \pm 0.4$ versus 1.9 \pm 0.3 years in patients with and without recovery of $\mathrm{AV}$ conduction, respectively (Table 2).

The median time to observed recovery of AV conduction was 41 days (range 18-113 days) after the initial operation. During a mean follow-up of $4.4 \pm 2.6$ years, there was no recurrence of $\mathrm{CHB}$ once $\mathrm{AV}$ conduction had recovered. Three patients had residual right bundle branch block and one had first-degree AV block.

\section{Discussion}

CHB remains a significant complication of surgery for congenital heart disease, with persistent AV block occurring in $1 \%$ to $3 \%$ of cardiac operations in the current era. In previous reports, one to two thirds of patients with $\mathrm{CHB}$ 
immediately after operation had recovery of AV conduction in the subsequent 2 weeks. ${ }^{2,10,15,16}$ Return of AV conduction in these patients appears reliable, and pacemaker implantation is generally not recommended ${ }^{14,17}$ Conversely, pacemaker implantation is a class I recommendation for patients with persistent postoperative AV block.

In prior reports, recovery of AV conduction after surgically induced $\mathrm{CHB}$ almost always occurs by the ninth postoperative day. ${ }^{2}$ For this reason, most patients with CHB continuing for 7 to 10 days after surgery have implantation of a permanent pacemaker. What has not been reported previously is the incidence of late recovery of sinus rhythm after pacemaker placement. This study shows a small but meaningful percentage of patients $(\sim 10 \%)$ have returned to normal sinus rhythm after prolonged CHB. This delayed return of $\mathrm{AV}$ conduction occurs within the first weeks to months after the operation. Once AV conduction had returned, intermittent or permanent loss of AV conduction was not observed, suggesting that lifelong cardiac pacing may not be necessary in these individuals.

Determination of the exact time of return of conduction was not possible, as monitoring was performed on a monthly basis. However, given the high rate of compliance in our program, the major limitation is that the return of $\mathrm{AV}$ conduction may have occurred within the 30-day interval between the preceding evaluation and the clinical or transtelephonic monitoring that identified return of conduction. Recovery of AV conduction was identified in 4 of 7 patients within the first 30-day postoperative interval.

Although the results are encouraging, continued follow-up is mandated for patients with late recovery of AV conduction due to the potential for paroxysmal AV block. Thus, they should be followed up like other pacemakerdependent patients. This should include evaluation with electrocardiograms and Holter monitoring. The pacemaker may be programmed to the lowest rate that would provide rate support in the event of a recurrence of $\mathrm{CHB}$.

The current ACC/AHA Guidelines for Pacemaker Implantation do not address the need for continuing pacemaker therapy in patients with persistent surgical AV block in whom AV conduction has returned. The limited number of patients in this study requires that these findings be verified by similar studies before a general recommendation can be made. Conversely, it is important to recognize that $\mathrm{AV}$ conduction did not recover in $90 \%$ of patients and that recovery could not be predicted based on clinical variables given the limited number of patients in this series. Consistent with current AHA/ACC Guidelines, we advocate that a pacemaker be implanted in patients with persistent postop- erative heart block lasting for 7 to 10 days. Furthermore, we advocate continued monitoring of patients who recover AV conduction, although the pacemakers may be reprogrammed to the VVI mode at a back-up rate less than the expected lowest normal sinus rate.

\section{References}

1. Lillehei CW, Sellers RD, Bonnabeau RC, Elliot RS. Chronic postsurgical complete heart block. J Thorac Cardiovasc Surg. 1963;46:43656.

2. Weindling SN, Saul PJ, Gamble WJ, Mayer JE, Wessel D, Walsh EP. Duration of complete atrioventricular block after congenital heart disease surgery. Am J Cardiol. 1998;82:525-7.

3. Bonatti V, Agnetti A, Squarcia U. Early and late postoperative complete heart block in pediatric patients submitted to open-heart surgery for congenital heart disease. Ped Med Chir. 1998;20:181-6.

4. Hokanson JS, Moller JH. Significance of early transient complete heart block as a predictor of sudden death late after operative correction of tetralogy of Fallot. Am J Cardiol. 2001;87:1271-7.

5. Driscoll DJ, Gillette PC, Hallman GL, Cooley DA, McNamara DG. Management of surgical complete atrioventricular block in children. Am J Cardiol. 1979;43:1175-80.

6. Hurwitz RA, Riemenschneider TA, Moss AJ. Chronic postoperative heart block in children. Am J Cardiol. 1968;21:185-9.

7. Liu L, Griffeths SP, Gerst PH. Implanted cardiac pacemakers in children: a report of their application in five patients. Am J Cardiol. 1967;20:639-47.

8. Murphy DA, Tynan M, Graham GR, Bonham-Carter RE. Prognosis of complete atrioventricular dissociation in children after open-heart surgery for congenital heart defects. Lancet. 1970;I:750-2.

9. Squarcia U, Merideth J, McGoon DC, Weidman WH. Prognosis of transient atrioventricular conduction disturbances complicating openheart surgery for congenital heart defects. Am J Cardiol. 1971;28:64852.

10. Kim MH, Deeb GM, Engle KA, Bruckman D, Pelosi F, Oral H, et al. Complete atrioventricular block after valvular heart surgery and the timing of pacemaker implantation. Am J Cardiol. 2001;87:649-51.

11. Moss AJ, Klyman G, Emmananoulides GC. Late onset complete heart block: newly recognized sequela of cardiac surgery. Am J Cardiol. 1972;30:884.

12. Banks MA, Jenson J, Kugler JD. Late development of atrioventricular block after congenital heart surgery in Down syndrome. Am J Cardiol. 2001;88:86-8.

13. Hokanson JS, Moller JH. Significance of early transient complete heart block as a predictor of sudden death late after operative correction of tetralogy of Fallot. Am J Cardiol. 2001;87:1271-7.

14. Gregoratos G, Cheitlin MD, Conill A, Epstein AE, Fellows C, Ferguson TB, et al. ACC/AHA guidelines for implantation of cardiac pacemakers and antiarrhythmia devices: a report of the American College of Cardiology/American Heart Association task force report on practice guidelines. J Am Coll Cardiol. 1998;31:1175-1209.

15. Kertesz N, McQuinn T, Collins E, Friedman R. Surgical atrioventricular block in 888 congenital heart operations: new implications for early implantation of a permanent pacemaker [abstract]. PACE. 1996; 19:613.

16. Glikson M, Dearani JA, Hyberger LK, Schaff HV, Hammill SC, Hayes DL. Indications, effectiveness, and long-term dependency in permanent pacing after cardiac surgery. Am J Cardiol. 1997;80:13009-13.

17. Krongrad E. Prognosis for patients with congenital heart disease and postoperative intraventricular conduction defects. Circulation. 1978; $57: 867-70$ 